\title{
Measuring the training external jump load of elite male volleyball players: an exploratory study in Portuguese League \\ Medición de la carga externa de entrenamiento de los jugadores de voleibol masculino de élite: un estudio exploratorio en la Liga Portuguesa
}

*Ricardo Franco Lima, **Jose Palao, ***Henrique Castro, ****Filipe Clemente

*Instituto Politécnico de Viana do Castelo - Escola Superior de Desporto e Lazer (Portugal) ; Research Center in Sports Sciences, Health Sciences and Human Development (CIDESD) (Portugal), **University of Wisconsin Parkside (Estados Unidos),

***Universidade Federal de Minas Gerais (Brasil), ${ }^{* * * *}$ Instituto Politécnico de Viana do Castelo - Escola Superior de Desporto e Lazer (Portugal); Instituto de Telecomunicações, Delegação da Covilhã (Portugal)

\begin{abstract}
The purpose of this exploratory study was to assess the external jump-training load of different playing positions in male professional volleyball players during regular competitive microcycles. Five male elite volleyball players participated in this study. The sample was composed by five male elite volleyball players of a team from Portugal's first division.was composed of 8,532 jumps were analyzed during 12 practice sessions of four competitive microcycles of the regular season (three practices in each microcycle). A descriptive design was implemented to analyze the number of jumps, jump heights, and rest time by players' playing positions (middle blockers, setter, and outside hitters), by training sessions, and by microcycles. The jump height and jump moment were recorded using an inertial measurement device. The setter made a significantly greater number of jumps than middle blockers and outside hitters. Middle blockers and outside hitters accumulate their jumps in specific moments (frontcourt). No significant differences were found in the jump intensity with player positions and with different training days of the microcycle. Significant lower amount of jumps were found on the training day before the competition. Results show how the coach modified the jump-training load of the session in the day prior to the competition.
\end{abstract}

Keywords: team sports, performance, monitoring, load, training.

Resumen. El propósito de este estudio exploratorio fue evaluar la carga externa de entrenamiento de salto de diferentes posiciones de juego en jugadores de voleibol profesionales masculinos durante microciclos competitivos regulares. Cinco jugadores masculinos de voleibol de élite participaron en este estudio. La muestra estuvo compuesta por cinco jugadores de voleibol de élite masculinos de un equipo de la primera división de Portugal. Se compuso de 8,532 saltos y se analizaron durante 12 sesiones de práctica de cuatro microciclos competitivos de la temporada regular (tres prácticas en cada microciclo). Se implementó un diseño descriptivo para analizar la cantidad de saltos, alturas de salto y tiempo de descanso por las posiciones de juego de los jugadores (bloqueadores medios, colocadores y bateadores externos), por sesiones de entrenamiento y por microciclos. La altura de salto y el momento de salto se registraron utilizando un dispositivo de medición inercial. Setter hizo un número significativamente mayor de saltos que los bloqueadores medios y los bateadores externos. Los bloqueadores medios y los bateadores externos acumulan sus saltos en momentos específicos primera línea. No se encontraron diferencias significativas en la intensidad del salto con las posiciones de los jugadores y con los diferentes días de entrenamiento del microciclo. Se encontró una cantidad de saltos significativamente menor en el día de entrenamiento antes de la competición. Los resultados muestran cómo el entrenador modificó la carga de entrenamiento de salto de la sesión en el día anterior a la competición.

Palabras clave: deporte en equipo, rendimiento, seguimiento, carga, entrenamiento.

\section{Introduction}

Volleyball is a collaborative competitive team sport, in which a net divides the court. The height of the net and size of the court made players do short and explosive actions (Sheppard, Gabbett, \& Stanganelli, 2009). The actions done near the net require the execution of jumps (e.g., spike and block). The jump ability is a critical motor skill in volleyball and allows players to perform better the game actions. Players of higher-level teams have higher jump abilities (Gabbett, Georgieff, \& Domrow, 2007; Sattler, Hadžic, Derviševic, \& Markovic, 2015). Thus, because jump ability is considered one of the most important action of the practice session, coaches need to focus on its development (Ziv \& Lidor, 2010). Although volleyball has a lower risk of injury incidence (2 to 4 injuries per 1,000 athlete exposures) than other team sports (Hootman, Dick, \& Agel, 2007), the most common injuries are in the lower body (Doherty et al., 2014). For that

Fecha recepción: 31-10-18. Fecha de aceptación: 25-05-19

Ricardo Franco Lim

ricardo.lima@esdl.ipvc.pt reason, it is recommended the inclusion of preventive actions and protocols to avoid this type of injuries in training sessions (Pastor, Ezechieli, Classen, Kieffer, \& Miltner, 2015).

Volleyball players do an average of 54-90 jumps per match and 45-128 jumps per hour of training (Bahr \& Bahr, 2014; Sheppard et al., 2009). However, the amount of jumps that players do depends on their role (Sheppard et al., 2009). The cause of these differences is that each player is responsible for different actions (set, spike or block), that involve different types of jumps (e.g., different approach and arms swing). Therefore, in order to design and adjust the training to needs of each player is critical to know the jump load of practice. Most of the studies done regarding the jump training demands in volleyball have used systematic observation. However, due to the time consuming procedures that this methodology involves, it is not possible the implementation of this approach in practice (Bahr \& Bahr, 2014). The introduction of recent technologies and validated devices that provide automatic information about the jumps done by the players can help to monitor the jump-training load of players in volleyball (Charlton, Kenneally-Dabrowski, Sheppard, \& Spratford, 2016). 
The changes in the training load can affect the preparedness of the players to competition (Bosquet, Montpetit, Arvisais, \& Mujika, 2007) and their recovery. Studies done in different team sports show that increases higher than 15\% in the weekly external loads, increased the risk of injuries to players (Gabbett, 2016). The proper modulation of the training load and its monitoring is critical to prepare properly the competition and to reduce the risk of injuries. The use of the automatic devices, such as inertial sensors, can also provide information about jump intensity and rest periods.

These knowledge, protocols and reference values can help volleyball coaches, and strength and conditioning coaches to know the external physical load that involves the jumps and to design and monitor training load. The aim of this exploratory study was to analyze the external jumptraining load of different players' position in male professional volleyball players during regular competitive microcycles.

\section{Methods}

\section{Participants}

Five male elite volleyball players of a team from Portugal's first division participated in this study (age $26.7 \pm 7.2$ years old, height $1.93 \mathrm{~m} \pm 0.08 \mathrm{~m}$, weight $86.5 \pm 6.3 \mathrm{~kg}$, and $5.14 \pm$ 5.35 years of experience in the first division). The sample was composed of 8,532 jumps done in 12 practice days of four competitive microcycles of the regular season of a professional team. Data were collected in three sessions of each microcycle (1,083 minutes of practice). The playing positions of the players analyzed were two middle blockers, one setter, and two outside hitters. Informed consent was obtained from all participants (players and coaches). An adaptation process for the research protocols was carried out before starting the data collection in practice (wearing the data collection devices). The study followed the ethical recommendations of Declaration of Helsinki for the study in humans.

\section{Measures}

A descriptive observational design was implemented in this exploratory study to analyze the number of jumps, jump heights, jump intensity, and rest time by players' playing positions (middle blockers, setter, and outside hitters), by session, and by microcycle. Data were collected during four weeks of the middle of the competition season (March 2017). The head coach and coaching staff planned all training sessions. Researchers did not influence at any level in the training planning. Players used an inertial measurement unit to assess the amount (n), moment (s), and jump height (m) during the entire training sessions. From these variables, the jumps per hour (n), ratio jump/time (s), average rest time (s), jump intensity (\%), and arbitrary units were calculated. The training sessions analyzed were: Tuesday, Thursday, and Friday. The team played its matches on Saturday.

\section{Design and Procedures}

To determinate the jump number and heights, each participant wore an inertial measurement unit device with three gyroscopes and three accelerometers (VERT Classic,
Florida, United States). This device was previously validated $(\mathrm{r}=0.83-0.97)$ by comparing it with a three-dimensional motion analysis (Charlton et al., 2016). The device has a small size ( $4.9 \mathrm{~cm}$ in length, $0.7 \mathrm{~cm}$ in width, and $0.021 \mathrm{~cm}$ in height) and is light $(0.022 \mathrm{~kg})$. The average standard error of the device for assessing the jump height is $4 \mathrm{~cm}$ (Charlton et al., 2016). The participants each wore a belt with the device on the hip.

Each inertial measurement unit was connected via Bluetooth to a tablet application. Data of the warm-up and cold down were not included in the study. The average duration of the main part of the practices was two hours on Tuesdays and Thursdays and one hour on Fridays. Players wore the device from the start of the warm-up until the end of the cooldown. The device transmitted data to the app in real time. After each session, all data were exported to a spreadsheet.

The data provided by the device was the jump height and the time in which each jump was done. The percentage of jump intensity (relative height) was calculated using the maximal jump done by each player. The jump intensity was expressed in percentage related to the maximal height jump. The time between jumps was calculated subtracting the time in which a jump was done to the time in which the previous jump was done. The time between jumps was expressed in seconds. Jump frequency was standardized using the hour as time unit reference ( $\mathrm{X}$ jumps per hour) and using the ratio of frequency ( 1 jump each $\mathrm{X}$ seconds). The arbitrary units of jump training load were calculated by multiplying the jump intensity by the number of jumps done.

Statistical Analysis

A descriptive (mean, standard deviation, and percentages) and an inferential analysis were performed using SPSS statistical analysis software (SPSS version 23.0, Chicago, USA). A MANOVA was used to test the interaction between days of the week and playing positions. As the following procedure, it was executed the one-way ANOVA to analyze the variations of jumps frequency, jump height, jump intensity and rest time between jump between days of the microcycle, and playing positions. The Tukey HSD Post Hoc test was used to analyze the influence of the different factors. The level of statistical significance was set at $p \mathrm{~d}$ » 0.05 .

The partial eta squared and the eta squared were used to calculate the effect sizes of the tests $\left(\eta_{p}^{2}\right.$ and $\left.\eta^{2}\right)$. Ferguson's classification for the $\eta^{2}$ was used to analyze the effect sizes (Ferguson, 2009): no effect (ES < 0.04); minimum effect (0.04 $<\mathrm{ES}<0.25)$; moderate effect $(0.25<\mathrm{ES}<0.64)$; and strong effect $(E S>0.64)$.

\section{Results}

Descriptive statistics of number of jumps, height jump, relative jump height, rest time between jumps, and jump load between playing position and training days can be found in Table 1 and Figure 1, respectively. Setter did a significant higher amount of jumps than middle blockers $(p=0.001, \mathrm{~d}=$ 1.214 , moderate effect) and outside hitters ( $p=0.001, \mathrm{~d}=$ 1.943 , moderate effect). Setter made significant lower jumps than middle blockers ( $p=0.001, \mathrm{~d}=1.614$, moderate effect) and outside hitters ( $p=0.001, d=2.032$, moderate effect). 
Outside hitters made significant higher jumps than middle blockers ( $p=0.006, \mathrm{~d}=0.784$, minimum effect). No significant differences were found in the relative intensity (\% of maximum jump) of the jumps done by the players of different positions ( $p=0.080 ; \eta^{2}=0.070$, minimum effect). No significant differences were found in number of jumps per hour between playing position with day of the training $\left(\mathrm{p}=0.736\right.$; $\eta_{\mathrm{p}}{ }^{2}=$ 0.031, no effect) and jump height $\left(p=0.151 ; \eta_{p}^{2}=0.100\right.$, minimum effect).

\begin{tabular}{|c|c|c|c|c|c|c|}
\hline \multicolumn{7}{|c|}{$\begin{array}{l}\text { Characteristics of the male elite volleyball players that participated in the study. } \\
\text { Subject }\end{array}$} \\
\hline Middle blocker \#1 & 20 & 2.07 & \multicolumn{2}{|c|}{91} & \multicolumn{2}{|c|}{5} \\
\hline Middle blocker \#2 & 36 & 1.93 & \multicolumn{2}{|c|}{90} & \multicolumn{2}{|c|}{20} \\
\hline Setter \#1 & 29 & 1.87 & \multicolumn{2}{|c|}{74} & \multicolumn{2}{|c|}{16} \\
\hline Outside hitter \#1 & 19 & 1.98 & \multicolumn{2}{|c|}{89} & \multirow{2}{*}{\multicolumn{2}{|c|}{$\begin{array}{c}4 \\
22\end{array}$}} \\
\hline Outside hitter \#2 & 34 & 1.94 & & & & \\
\hline \multicolumn{6}{|c|}{$\begin{array}{l}\text { Average amount of jumps, jump frequency, jump heights, jump intensity and arbitrary units in } \\
\text { practice for male volleyball players of different positions. }\end{array}$} & \\
\hline & \multicolumn{2}{|c|}{ Middle blocker } & \multicolumn{2}{|c|}{ Setter } & \multicolumn{2}{|c|}{ Outside hitter } \\
\hline Variable & Average & SD & Average & SD & Average & SD \\
\hline Jumps (n) & 123.3 & 54.3 & $179.9^{\mathrm{a}, \mathrm{b}}$ & 64.0 & 141.7 & 63.1 \\
\hline Jumps per hour (n) & 77.5 & 22.0 & 118.0 & 10.8 & 90.7 & 23.4 \\
\hline Ratio jump/time (s) & $1: 53.0$ & 27.8 & $1: 30.7$ & 2.8 & $1: 42.3$ & 11.8 \\
\hline Average rest time (s) & 23.4 & 7.8 & 27.9 & 2.6 & 20.7 & 5.3 \\
\hline Height (cm) & $48.0^{\mathrm{b}, \mathrm{c}}$ & 4.4 & $41.1 \mathrm{a}, \mathrm{b}$ & 2.5 & 51.0 a,c & 4.0 \\
\hline Intensity (\%) & 51.6 & 4.8 & 57.8 & 3.5 & 54.6 & 4.0 \\
\hline Arbitrary Units & 62.2 & 26.2 & $105.6^{\mathrm{a}, \mathrm{b}}$ & 40.4 & 78.8 & 37.5 \\
\hline
\end{tabular}

A significant higher amount of jumps were found between days of the week for all players positions studied ( $\mathrm{p}=0.001$; $\eta^{2}=0.303$, moderate effect) (Figure 1 ).

Significant fewer number of jumps were done on Friday than on Tuesday ( $p=0.001, d=1.352$, moderate effect) or Thursday ( $p=0.001, d=1.369$, moderate effect). No significant differences were found in the jump height $\left(p=0.799 ; \eta^{2}=\right.$ 0.006 , no effect) and jump relative intensity $\left(p=0.481 ; \eta^{2}=\right.$ 0.021 , no effect) between the different days of the week.

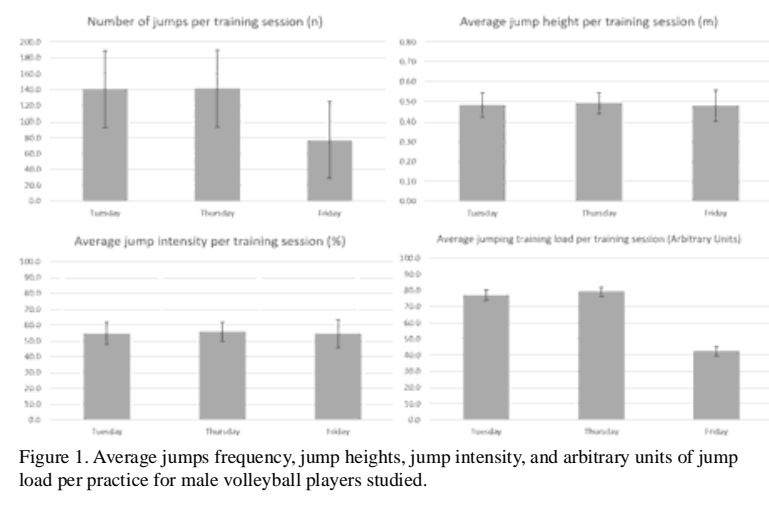

\section{Discussion}

The aim of the study was to analyze the jump-training load of different players' position in different sessions of competitive microcycles. The results showed differences in the total of jumps done, their intensity and their frequency for the different player positions per training session. The setters did a higher amount of jumps than outside hitters and middle blockers. However, the analysis of the ratios of jump/ time and the rest time of each player position show different distributions of these jumps for each player during the practice session. The reason for these differences may be caused by the rotation rule and attack rule (rules 7.4, 7.6 and 14, FIVB, 2016). All players have to rotate for the different zones of the court: frontcourt and backcourt. The players' participation changes when the players are in the frontcourt, due to they can attack and block near to the net. Therefore, middle blockers and outside hitters perform a lower number of jumps and had a smaller ratio jump/time because their participation is accumulated in three rotations. However, their rest between jumps is smaller, due to they have a higher frequency of jumps in these rotations. The distribution of the jumps done by the setter is different. The setter can execute jumps to sets in all the rotations. When setter is in the frontcourt, their jump load can increase due to he participates in block actions when the opponent's attack is done by their side of the net.

These differences between players positions in the number of jumps done have also been found in previous studies (Sattler et al., 2015). The results found show a higher amount of jumps done by the different player position in practice than previous studies (Bahr \& Bahr, 2014; Sheppard et al., 2009). The causes of these differences can be due to the level of the team, due to training involved more continuity in the task and exercises, more intensity in the task, or higher usage of the use of jump set. Previous, studies focused on the total amount of jumps performance for each position. These findings related to jump distribution show that physical training for each position should be design and analyze in a different way. The distribution of the jumps during the practice is an important aspect to consider in the design and monitoring of training. Setters do a large number of jumps, spread during practice, and during all rotation and game phases. However, middle blockers and outside hitters accumulated their jumps in specific periods of the practice.

After these periods, they have jump rest periods. This aspect involves that in order to analyze properly the jump training load for these players besides the total number of jumps, and the jumps per hour (normalize data), it should be considered the rest periods between jumps and the rest periods between groups of jumps (frontcourt rotations). More studies are needed to establish the specific jump demands for these players and the best metrics to monitor these athletes in practice and in competition.

The analysis of the jump height and the jump intensity showed complementary information of the actions done by the different players' position. When we analyze the jump height, outside hitters jumped higher than setter and middle blocker, respectively. However, regarding to relative jump height, when we analyze the intensity of the jumps the values are similar. One of the reasons behind these results is the manner of execution of the actions done by the players, specifically the approach and the arms swing (Ziv \& Lidor, 2010).

Other possible aspects that influence are the player's positions, anthropometry and the context of the task and the jumps. Most of the jumps done by the outside hitter are spikes.

The spike is executed with an approach and arms swing. Most of the jumps done by the middle blockers are blocks and spikes because of their specificity in the game. The block is executed without approach or with a lateral approach and with a short arm swing. Most of the jumps done by the setters are done to set, although they also do blocks. The goal of the jump set is to increase the ball contact height 
without losing precision in the pass. The jump set is executed without approach or with a control approach and without arms swing. The way of execution affects the jump height, for that reason, it is recommended to use the maximum height jump values for each type of jump of each player to calculate the jumps intensity (\%) in order to establish properly the jump-training load.

The use of the inertial sensors provides the jump height, which enables us to calculate the jump intensity. This information allows new insights into the analysis of jumptraining load. The combination of the volume and intensity enables the calculation of the arbitrary units of the jump load in practice. However, to avoid errors calculating the jump intensity, it is necessary to complement the data collected from the automatic devices with the information about the context and the type of actions through video analysis. This aspect can affect the data collected and its analysis. This is a limitation of the data obtained using the current devices that quantify automatically the jumps.

It is known that activities that improve players decisionmaking abilities should be recommended during the training session and the specificity of training must be expressed by the proximity of the velocities of execution of the training exercises (Asencio, Sanchez-Moreno, \& González-Badillo, 2016; Suarez, Rabaz, Férnandez-Echeverría, Gil-Arias, \& Moreno, 2017).

Unfortunately, in this study, the training sessions were not recorded and it was not possible to know the type of jumps done by the players. Future studies are needed to establish the validity of these assessments with and without considering the type of jump done. Future technological devices should consider the players' role, the acceleration of their actions, the type of displacement, etc. (e.g., approach previously to the jump) to contextualize properly the jumps done by the players and establish the jump intensity.

The information provided by these devices allows coaches to analyze the way coaches adapt the jump-training load the day previous to the competition. Data show how Tuesday and Thursday practices involved more jumps than Friday, and the intensity of these jumps was similar in the different sessions analyzed. These results can be considered as a normal adaptation to team sports of the recommendations of the literature related to tapering process: reduction of the volume, maintaining the intensity the previous day to the game (Bosquet et al., 2007). The use of this type of device can provide information in real-time to coaches that allow them to know when the desire jump volume is reached for each player. These devices provide objective information that can help coaches to adjust the length of training in the tapering process. Strength and conditioning coaches and sport performance researchers, using these devices, have new possibilities to measure and analyze the external load during the training sessions (Charlton et al., 2016).

It must be considered that this paper is an exploratory study and it has some limitations. The number of participants and data collected were small, what it does not allow to generalize the results. However, the paper presents information about the usage of different metrics to calculate the jumps load. Future studies must assess the spatiotemporal aspects of the jumps associate to repeated- jump series and its fatigue (e.g., frontcourt) and collect the type of jumps done by the players in order to establish properly their intensity.

\section{Conclusions}

This study shows the possibilities that the use of automatic devices offers to monitor of volume, height, intensity, and rest periods of the jumps done in training. This information enables us to analyze the jump-training load, the tapering process, or the training specificity that the jumps involve. Players' role and type of actions are aspects that should be considered in the analysis of jump training load. The calculation of jump intensity must consider the type of jump done by the player, due to the type of approach, and the arms swing affect the jump. Results of this study show total jumps, jumps per time, jump intensity, rest time between jumps and arbitrary jump units as possible metrics to use in the analysis of the jump-training load.

Results show that setter made a significantly greater number of jumps than middle blockers and outside hitters, with similar intensity and distribute uniformly through the training practice. However, middle blockers and outside hitters accumulated their jumps in specific moments (frontcourt). These results show that monitoring the jumptraining load of volleyball players should consider their role and specific characteristics (jump capacity). This research showed how the coach reduced the jump volume the previous day to the match with respect to previous training sessions as a way to prepare the competition. Players did not change the intensity of their jumps the previous session to the match. More studies are needed to provide information about jump training load in volleyball players.

\section{References}

Asencio, G., Moreno, S., Badillo, G., \& José, J. (2016). Entrenamiento combinado de fuerza y ejercicios de saltos , efectos sobre el rendimiento en el salto vertical en un grupo de alto nivel de jugadores de voleibol durante una temporada completa de competición. Retos, 2041, 140143.

Bahr, M.A., \& Bahr, R. (2014). Jump frequency may contribute to risk of jumper's knee: a study of interindividual and sex differences in a total of 11943 jumps video recorded during training and matches in young elite volleyball players. British Journal of Sports Medicine, 48(17), 1322-1326. https://doi.org/10.1136/bjsports-2014-093593

Bosquet, L., Montpetit, J., Arvisais, D., \& Mujika, I. (2007). Effects of Tapering on Performance. Medicine \& Science in Sports \& Exercise, 39(8), 1358-1365. https://doi.org/ 10.1249/mss.0b013e31806010e0

Charlton, P. C., Kenneally-Dabrowski, C., Sheppard, J., \& Spratford, W. (2016). A simple method for quantifying jump loads in volleyball athletes. Journal of Science and Medicine in Sport. https://doi.org/10.1016/ j.jsams.2016.07.007

Doherty, C., Delahunt, E., Caulfield, B., Hertel, J., Ryan, J., \& Bleakley, C. (2014). The Incidence and Prevalence of Ankle Sprain Injury: A Systematic Review and Meta-Analysis 
of Prospective Epidemiological Studies. Sports Medicine, 44(1), 123-140. https://doi.org/10.1007/s40279-0130102-5

Feltner, M. E., Bishop, E. J., \& Perez, C. M. (2004). Segmental and Kinetic Contributions in Vertical Jumps Performed with and without an Arm Swing. Research Quarterly for Exercise and Sport, 75(3), 216-230. https://doi.org/ 10.1080/02701367.2004.10609155

Gabbett, T., Georgieff, B., \& Domrow, N. (2007). The use of physiological, anthropometric, and skill data to predict selection in a talent-identified junior volleyball squad. Journal of Sports Sciences, 25(12), 1337-1344. https:// doi.org/10.1080/02640410601188777

Gabbett, T. J. (2016). The training - injury prevention paradox: should athletes be training smarter and harder? British Journal of Sports Medicine, 50(5), 273-280. https:// doi.org/10.1136/bjsports-2015-095788

Hootman, J. M., Dick, R., \& Agel, J. (2007). Epidemiology of Collegiate Injuries for 15 Sports: Summary and Recommendations for Injury Prevention Initiatives. Journal of Athletic Training, 42(2), 311-319.

Pastor, M., Ezechieli, L., Classen, L., Kieffer, O., \& Miltner, O. (2015). Prospective study of injury in volleyball players: 6 year results. Technology and Health Care, 23, 637643. https://doi.org/10.3233/THC-151009
Sattler, T., Hadžic, V., Derviševic, E., \& Markovic, G. (2015). Vertical jump performance of professional male and female volleyball players: Effects of playing position and competition level. Journal of Strength and Conditioning Research, 29(6), 1486-1493. https://doi.org/10.1519/ JSC.0000000000000781

Sheppard, J. M., Gabbett, T. J., \& Stanganelli, L.-C. R. (2009). An Analysis of Playing Positions in Elite Men $1 / 4 \mathrm{~S}$ Volleyball: Considerations for Competition Demands and Physiologic Characteristics. Journal of Strength and Conditioning Research, 23(6), 1858-1866. https:// doi.org/10.1519/JSC.0b013e3181b45c6a

Conejero Suárez, M., Claver Rabaz, F., Fernández-Echeverría, C., Gil-Arias, A., \& Moreno Arroyo, M. P. (2017). Toma de decisiones y rendimiento en las acciones de juego intermedias y finalistas en voleibol, en sets con diferente resultado. / Decision-making and performance in intermediate and terminal actions in volleyball according to the set result. Retos: Nuevas Perspectivas de Educación Física, Deporte y Recreación, 31, 28-33.

Ziv, G., \& Lidor, R. (2010). Vertical jump in female and male volleyball players: A review of observational and experimental studies. Scandinavian Journal of Medicine and Science in Sports, 20(4), 556-567. https://doi.org/10.1111/ j.1600-0838.2009.01083.x

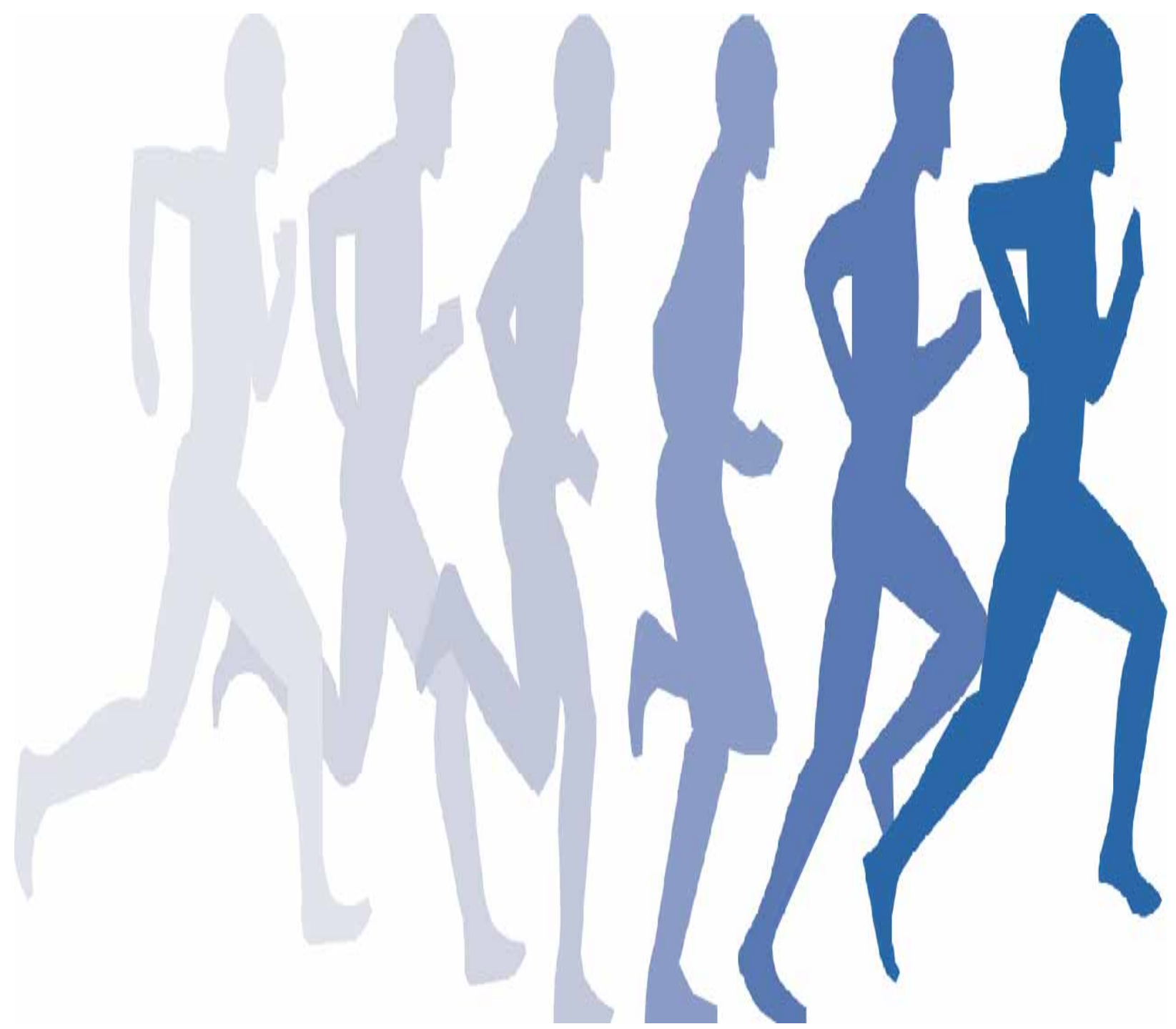

